\title{
GC-MS AND HEAVY METAL ANALYSIS OF GASCA D HERBAL FORMULATION
}

Ibrahim S. Ismail ${ }^{1 *}$, Ibrahim, D. Gezawa ${ }^{2,3}$, Muhammed F. Yahya ${ }^{3}$, Bashir Chedi ${ }^{4}$, Kabir Nafisatu $^{1}$, Imam A. $A^{5}$

\section{Affiliation}

1. Department of Biochemistry, Federal University Dutse

2. Department of Medicine, Aminu Kano Teaching hospital

3. Department of Medicine, Abdullahi Wase Specialist Hospital, Kano

4. Department of Pharmacology, Bayero University Kano

5. Department of Biochemistry, Bayero University Kano

\author{
*Correspondence \\ Department of Biochemistry \\ Federal University Dutse Nigeria \\ $+2348036316108$ \\ salihu.ibrahim@fud.edu.ng
}

\begin{abstract}
Gasca D herbal formulation is an antidiabetic medicine for the management of diabetes mellitus produced exclusively from natural ingredients. The level of some essential elements (Copper, chromium, Cobalt, Iron, Manganese, Nickel and zinc) and toxic (Cadmium, Arsenic, Mercury, and Lead) heavy metals were determined using microwave plasma-atomic emission spectrometry (MP-AES). The aim of this study is to evaluate the levels of essential and toxic heavy metals and also identify bioactive compounds present in Gasca D herbal formulation. The result shows no traces of Lead, Mercury, Zinc, Arsenic and Zinc, Iron was found to have highest concentration $67.16 \pm 7.5 \mu \mathrm{g} / \mathrm{g}$ and Cadmium lowest concentration $0.4 \pm 0.03 \mu \mathrm{g} / \mathrm{g}$. GC-MS analysis of Gasca D herbal formulation revealed the presence of 14 biologically active compounds which include NFormyl-beta-alanine, Paromomycin, 3,4-Altrosan, Benzamide, 1,3,4-Thiadiazol-2-amine, Carbamodithioic acid, Carbonic acid, alpha-D-Glucopyranoside, Ethyl isocyanide, 2Propanesulfinic acid, Propanamide, 2-Butenenitrile, Dicyclopropyl carbinol, Isoxazolidine, 1,5Hexadiene 10-Azido-1-decanethiol. Conclusion: The result indicates that the mean levels of toxic metals in Gasca D herbal formulation were below WHO permissible levels. Gasca D herbal formulation also contains various bioactive compounds that can have various medicinal application which can be used for the treatment of various diseases.
\end{abstract}




\section{Introduction}

In all countries of the world there exists traditional knowledge related to the health of humans and animals. In Africa, traditional healers and remedies made from plants play an important role in the health of millions of people. In Africa there is wide disparity between the relative ratios of traditional practitioners and university trained doctors in relation to the whole population. This may be reason why almost eighty per cent of African populations use some form of traditional herbal medicine [1,2].

With the ever-increasing use of herbal medicines worldwide, the safety and quality of medicinal plant materials and finished herbal medicinal products have become a major concern for health authorities, pharmaceutical industries and the public.It is estimated that up to four billion people (representing $80 \%$ of the world's population) living in the developing world rely on herbal medicinal products as a primary source of healthcare and traditional medical practice which involves the use of herbs is viewed as an integral part of the culture in those communities [3-5]. As the global use of herbal medicinal products continues to grow and many more new products are introduced into the market, public health issues, and concerns surrounding their safety are also increasingly recognized. Although some herbal medicines have promising potential and are widely used, many of them remain untested and their use also not monitored. This makes knowledge of their potential adverse effects very limited and identification of the safest and most effective therapies as well as the promotion of their rational use more difficult [1].

It has become necessary to investigate herbal medicinal products to facilitate better understanding of the risks associated with the use of these products and to ensure that all medicines are safe and of suitable quality.

Medicinal plants, unlike pharmacological drugs, commonly have several chemicals working together catalytically and synergistically to produce a combined effect that surpasses the total activity of the individual constituents. The combined actions of these substances tend to increase the activity of the main medicinal constituent by speeding up or slowing down its assimilation in the body. Secondary metabolites from plant's origins might increase the stability of the active compound(s) or phytochemicals, minimize the rate of undesired adverse side effects, and have an additive, potentiating, or antagonistic effect.

However the safety levels of these herbal remedies are not fully investigated. Most herbal medicines are not subjected to rigorous scrutiny in terms of safety and efficacy as is the case for conventional western medicine, and heavy metals have been reported in some of these herbal products [6,7]. These heavy metals constitute health risk to users because they bioaccumulate in the body when ingested via fluids, food or through other sources of contamination and are stored faster than they are broken down or excreted [7,8]. These shows that there is urgent need to investigative in order to determine the concentration of the some toxic metals which pose significant health risk to people. The need for safety assessment and quality assurance of plant products has been highlighted by the WHO. It seems compulsory that all herbal preparations and raw materials be investigated for the presence of heavy metals [9].

The main aim of this study is to quantify the level of some selected toxic metals such as arsenic, cadmium, lead and mercury in Gasca D herbal products manufactured by Greenleaf herbal product in Kano, Nigeria.

\section{MATERIALS AND METHODS}

Reagents: Analytical grade nitric acid, hydrochloric acid (Sigma aldrich). 


\section{Digestion of the samples}

Gasca D herbal sample with mass $5 \mathrm{~g}$ was weighed and dissolved in $10 \mathrm{~mL}$ of mixed acid $\left(\mathrm{HNO}_{3} / \mathrm{HCl}\right.$ in the ratio 1:3) for $12 \mathrm{hr}$. The mixture was heated on a hot plate until the brown fumes changed to white. It was allowed to cool and $10 \mathrm{~mL}$ of distilled water was added and again heated again. The mixture was then filtered into $50 \mathrm{~mL}$ volumetric flask after cooling. The final volume was made up to $50 \mathrm{~mL}$ with deionized water. Reagent blank was also carried out in the same way. All measurements were done in duplicate for the sample and standard solution.

\section{Instrumentation}

Agilent $4100 \mathrm{MP}$-AES was used for the total metal determination of $\mathrm{Zn}, \mathrm{Cu}, \mathrm{Pb}, \mathrm{Fe}, \mathrm{Mo}, \mathrm{Hg}, \mathrm{Si}$, $\mathrm{V}, \mathrm{Cd}, \mathrm{Ni}, \mathrm{Co}, \mathrm{Mn}, \mathrm{Cr}, \mathrm{Al}$ and As in Gasca D herbal formulation. The viewing position and nebulizer pressures were optimized automatically using the Agilent MP Expert software. Manual sample introduction mode was used. Table 1 lists the Agilent 4100 MP-AES operating conditions

\section{Table 1: Agilent 4100 MP-AES operating conditions}

\begin{tabular}{|l|l|}
\hline Instrument parameter & Setting \\
\hline Nebulizer & Concentric \\
\hline Spray chamber & Single-pass glass cyclonic \\
\hline Sample tubing & Black/black \\
\hline Waste tubing & Blue/blue \\
\hline Read time & $3 \mathrm{~s}$ \\
\hline Number of replicates & 2 \\
\hline Stabilization time & $10 \mathrm{~s}$ \\
\hline Fast pump during sample uptake & On \\
\hline Pump speed & $15 \mathrm{rpm}$ \\
\hline
\end{tabular}

\section{Calibration}

Analytical calibration was carried out using multi-element standard solutions, except for As. Separate calibration solutions were used for As because of the Fe spectral interference on the As $234.984 \mathrm{~nm}$ emission line.

\section{Background and interference corrections}

The auto-background correction feature in the MP Expert software was used for background correction. Fast Linear Interference Correction (FLIC), an Agilent proprietary spectral interference correction method, was used to correct and remove the iron interference on determination of As using the $234.984 \mathrm{~nm}$ line.

\section{Gas chromatography-mass spectrometry (GC-MS) analysis}

The Gasca D herbal formulation powdered sample was dissolved in HPLC grade methanol to appropriate concentrations for GC-MS analysis, and was analyzed by GC-MS on an Agilent $6890 \mathrm{~N}$ series gas chromatograph coupled with a LECO time of flight mass spectrometer detector (MS-TOF; Agilent Technology, Santa Clara, CA) with ionization voltage of $70 \mathrm{eV}$ and equipped with fused silica non-polar DB-5 capillary column $(10 \mathrm{~m} \mathrm{x} 0.18 \mathrm{~mm}$; film thickness $0.18 \mathrm{~mm}$; Agilent HP). The operating conditions were as follows: the injector operated in split mode (ratio 
20:1) and mass spectrometer transfer line temperatures were set at 200 and $300{ }^{\circ} \mathrm{C}$, respectively; the oven temperature gradually rose from 40 to $260^{\circ} \mathrm{C}$, at warming rate of $4{ }^{\circ} \mathrm{C} \mathrm{min}{ }^{-1}$, kept at 260 ${ }^{\circ} \mathrm{C}$ during $20 \mathrm{~min}$, and finally up to $340^{\circ} \mathrm{C}$, at a warming rate of $4{ }^{\circ} \mathrm{C} \mathrm{min}{ }^{-1}$ for $20 \mathrm{~min}$ isothermally; the injector temperature was set at $300^{\circ} \mathrm{C}$. The carrier gas $(\mathrm{He})$ was set to $1 \mathrm{~mL} \mathrm{~min}^{-1}$ flow. Mass analyzer was used in full scan mode scanning from $\mathrm{m} / \mathrm{z} 40-550$ and mass spectra were taken at 70 $\mathrm{eV}$. Compounds were identified by coinjection of the sample with standard references by comparison of their mass spectral data with those of NIST Mass Spectral Library 98 and equipment Libraries as well as by comparison of their retention indices (RIs).

\section{RESULTS}

The element with the highest concentration found in Gasca D herbal formulation is iron 67.16 $\mu \mathrm{g} / \mathrm{g}$, followed by aluminium with a concentration of $16.84 \mu \mathrm{g} / \mathrm{g}$. The concentrations of Lead, Zinc, Mercury, Silicon, Arsenic and Molybdenum were not detected at all; the values were $0.0 \mu \mathrm{g} / \mathrm{g}$, $0.0 \mu \mathrm{g} / \mathrm{g}, 0.0 \mu \mathrm{g} / \mathrm{g}, 0.0 \mu \mathrm{g} / \mathrm{g}, 0.0 \mu \mathrm{g} / \mathrm{g}$ and $0.0 \mu \mathrm{g} / \mathrm{g}$ respectively (Table 2). Cadmium and Chromiun were found in trace amount at a concentration of $0.4 \mu \mathrm{g} / \mathrm{g}$ and $0.72 \mu \mathrm{g} / \mathrm{g}$ respectively. Other elements found in Gasca $\mathrm{D}$ herbal formulations are $\mathrm{Cu}, \mathrm{V}, \mathrm{Ni}$, Co and $\mathrm{Mn}$ with relative concentrations of $1.6 \mu \mathrm{g} / \mathrm{g}, 2.6 \mu \mathrm{g} / \mathrm{g}, 1.72 \mu \mathrm{g} / \mathrm{g}, 1.64 \mu \mathrm{g} / \mathrm{g}$ and $7.72 \mu \mathrm{g} / \mathrm{g}$ respectively (Table 2).

\section{Table 2: Result for the analysis of Gasca D}

\begin{tabular}{|l|l|}
\hline Analyte & $\begin{array}{l}\text { MP-AES results } \\
\text { Average } \pm \text { SD }(\mu \mathrm{g} / \mathrm{g})\end{array}$ \\
\hline $\mathrm{Zn}$ & $0 \pm 0$ \\
\hline $\mathrm{Cu}$ & $1.6 \pm 0.4$ \\
\hline $\mathrm{Pb}$ & $0 \pm 0$ \\
\hline $\mathrm{Fe}$ & $67.16 \pm 7.5$ \\
\hline $\mathrm{Mo}$ & $0 \pm 0$ \\
\hline $\mathrm{Hg}$ & $0 \pm 0$ \\
\hline $\mathrm{Si}$ & $0 \pm 0$ \\
\hline $\mathbf{V}$ & $2.6 \pm 0.7$ \\
\hline $\mathrm{Cd}$ & $0.4 \pm 0.03$ \\
\hline $\mathbf{N i}$ & $1.72 \pm 0.05$ \\
\hline $\mathrm{Co}$ & $1.64 \pm 0.1$ \\
\hline $\mathrm{Mn}$ & $7.72 \pm 0.9$ \\
\hline $\mathrm{Cr}$ & $0.72 \pm 0.04$ \\
\hline $\mathrm{Al}$ & $16.84 \pm 1.7$ \\
\hline As & $0 \pm 0$ \\
\hline
\end{tabular}

\section{GC-MS analysis of compounds identified in Gasca D herbal formulation}

The GC-MS analysis of Gasca D herbal formulation revealed the presence 14 main compounds. The compounds are listed in (Table 3); shown are the phytocomponents retention time, molecular formula 
and molecular weight (MW). The examination of Gasca D herbal formulation allowed the identification of a very important antibiotic paromomycin and Thiadiazol derivative which is a new class of carbonic anhydrase inhibitors, the herbal formulation was found to have higher amounts of carbonic acid appearing at different peak interval, derivatives of amide, nitrile were also identified (Table 3).

Table 3: Phytocomponents identified in the Gasca D herbal formulation by GC-MS analysis

\begin{tabular}{|c|c|c|c|c|c|}
\hline$S / N$ & Compound Name & PEAK & R.TIME (s) & M. Formula & M.Wt. (g/mol) \\
\hline 1 & 1,5-Hexadiene & 7 & 58.8 & $\mathrm{C}_{6} \mathrm{H}_{10}$ & 82.143 \\
\hline 2 & 2-Propanesulfinic acid & 10 & 60.6 & $\mathrm{C}_{3} \mathrm{H}_{8} \mathrm{O}_{2} \mathrm{~S}$ & 108.161 \\
\hline 3 & Propanamide & 16 & 64.5 & $\mathrm{C}_{3} \mathrm{H}_{7} \mathrm{NO}$ & 73.095 \\
\hline 4 & 2-Butenenitrile & 18 & 66.4 & $\mathrm{C}_{4} \mathrm{H}_{5} \mathrm{~N}$ & 67.091 \\
\hline 5 & Dicyclopropyl carbinol & 19 & 67.0 & $\mathrm{C}_{7} \mathrm{H}_{12} \mathrm{O}$ & 112.1696 \\
\hline 6 & $\begin{array}{l}\text { Isoxazolidine, } \\
\text { 10-Azido-1-decanethiol }\end{array}$ & 21 & 69.2 & $\begin{array}{l}\mathrm{C}_{3} \mathrm{H}_{7} \mathrm{NO} \\
\mathrm{C}_{10} \mathrm{H}_{21} \mathrm{~N}_{3} \mathrm{~S}\end{array}$ & $\begin{array}{l}73.095 \\
215.359\end{array}$ \\
\hline 7 & Ethyl isocyanide & 23 & 70.8 & $\mathrm{C}_{3} \mathrm{H}_{5} \mathrm{~N}$ & 55.08 \\
\hline 8 & alpha-D-Glucopyranoside & 27 & 74.1 & $\mathrm{C}_{6} \mathrm{H}_{12} \mathrm{O}_{6}$ & 180.156 \\
\hline 9 & Carbonic acid & $30 ; 32 ; 33 ; 40$ & $\begin{array}{l}75.8 ; \\
76.4 ; 76.7 ; 80.4\end{array}$ & $\mathrm{CH}_{2} \mathrm{O}_{3}$ & 62.024 \\
\hline 10 & Carbamodithioic acid & 31 & 76.0 & $\mathrm{C}_{3} \mathrm{H}_{7} \mathrm{NS}_{2}$ & 121.224 \\
\hline 11 & 1,3,4-Thiadiazol-2-amine & 36 & 77.8 & $\mathrm{C}_{2} \mathrm{H}_{3} \mathrm{~N}_{3} \mathrm{~S}$ & 101.127 \\
\hline 12 & $\begin{array}{l}\text { Paromomycin } \\
\text { 3,4-Altrosan }\end{array}$ & 38 & 78.8 & $\mathrm{C}_{23} \mathrm{H}_{45} \mathrm{~N}_{5} \mathrm{O}_{14}$ & 615.634 \\
\hline 13 & Benzamide & $44 ; 47$ & 85.8 & $\mathrm{C}_{7} \mathrm{H}_{7} \mathrm{NO}$ & 121.139 \\
\hline 14 & N-Formyl-beta-alanine & 20 & 68.309 & $\mathrm{C}_{4} \mathrm{H}_{7} \mathrm{NO}$ & 117.103 \\
\hline
\end{tabular}

\section{DISCUSSION}


It is well known that heavy metals in herbal products pose a substantial health hazard due to their toxic and mutagenic effects, regardless of the concentration levels [10]. Herbs are taken in different forms as teas, syrup, essential oils, capsules and tablets. The world health organization has mandated all medicinal plants which form the raw material for the finished product must be checked for the presence of heavy metal and pesticide residues [11]. Result of the present study showed no traces of Lead, Mercury, Silicon, Arsenic, Molybdenum and Zinc (Table 2). The lack of any detectable amount of the above metals in Gasca D herbal formulation is an indication that the Gasca D herbal formulation may not pose serious health hazard to human health, as most of these heavy metals are found to be toxic in high concentration to most of the major organs such as kidney, liver, renal tract, cardiovascular, reproductive and others [12]. This shows that the formulation can be safe for consumption.

Toxicity of Cadmium can occur if their concentration is found to be above the permissible limit set by WHO, China and Thailand as $0.3 \mu \mathrm{g} / \mathrm{g}$ in medicinal herbs [13]. The level of Cadmium found in the present study was $0.4 \mu \mathrm{g} / \mathrm{g}$ which is much lower than the permissible limit of $30 \mu \mathrm{g} / \mathrm{g}$ [13]. Gasca D herbal formulation was found to have Cd level lower than most herbal formulation being sold in Nigeria. Chionyedua et al. [14] reported the level of $\mathrm{Cd}$ in some popular registered herbal formulation sold in Nigeria such as E-5000, YC-BITTER and B-CAPS had Cd concentration of $0.48 \mu \mathrm{g} / \mathrm{g}, 0.52 \mu \mathrm{g} / \mathrm{g}$ and $3.08 \mu \mathrm{g} / \mathrm{g}$ respectively. The calculated daily limit of Canada natural product daily limit for cadmium is $8.5 \mu \mathrm{g} / \mathrm{g}$ [15]. This shows that the cadmium level of Gasca D herbal formulation is far below the maximum daily limit set by Canada, and it may thus not pose any significant health risk. Chromium is an essential micronutrient, but it becomes toxic at high levels, and chronic exposure to $\mathrm{Cr}$ may result in liver, kidney and lung damage [16]. The level of chromium found in the present study was $0.72 \mu \mathrm{g} / \mathrm{g}$ which is lower than the tolerable upper intake level of $30 \mu \mathrm{g} /$ day [17]. The permissible limit for chromium in herbal medicinal plants/finished products have not been set by the World Health Organization but the Cr level in Gasca D herbal formulation may not pose serious health effect to humans. The $\mathrm{Cu}, \mathrm{Ni}$, and $\mathrm{Mn}$ content of Gasca $\mathrm{D}$ herbal formulation with relative concentrations of $1.6 \mu \mathrm{g} / \mathrm{g}, 1.72 \mu \mathrm{g} / \mathrm{g}$, and $7.72 \mu \mathrm{g} / \mathrm{g}$ respectively were all found to be below the concentration of many herbal formulations and also below the tolerable upper intake level of $\mathrm{Cu}, 900 \mu \mathrm{g} / \mathrm{g}, \mathrm{Ni}, 1000 \mu \mathrm{g} / \mathrm{g}$ and $\mathrm{Mn}, 2000 \mu \mathrm{g} / \mathrm{g}$ respectively as reported by Bogdan and Marek, [17]. The cobalt concentration of $1.64 \mu \mathrm{g} / \mathrm{g}$ obtained in this work is lower than the one reported by Jabeen et al. [18], in which seven herbal medicines used in Turkey had $(0.14 \mathrm{mg} / \mathrm{kg}-0.48 \mathrm{mg} / \mathrm{kg})$.

Vanadium an element of the transition metals is present in the air and soil contaminants in large urban agglomerations due to combustion of fossil fuels. It forms numerous inorganic compounds (vanadyl sulfate, sodium metavanadate, sodium orthovanadate, vanadium pentoxide) as well as complexes with organic compounds (BMOV, BEOV, METVAN). Vanandium concentration of Gasca D herbal formulation was found to be $2.6 \mu \mathrm{g} / \mathrm{g}$. At ambient conditions, the daily oral intake of vanadium via potable water and food varies between $10 \mu \mathrm{g}$ and $2 \mathrm{mg}$. This is clearly beyond the no-effect level of $10 \mathrm{mg}$ vanadium per day and per $\mathrm{kg}$ body mass [19]. Vanadium compounds lower blood glucose levels in animals and in clinical trials. They also inhibit the activity of protein tyrosine phosphatase 1B. Vanadium compounds, in particular organic derivatives, have insulinmimetic and antidiabetic properties. The presence of Vanadium in Gasca D herbal formulation is evidence that it might have played a significant role in reduction of blood glucose concentration found in Alloxan induced diabetic rats that received Gasca D at $1,000 \mathrm{mg} / \mathrm{kg}$ bw. Therapeutic properties of vanadium compounds in diabetes appeared as early as 1899 [20]. Studies performed in diabetic patients, confirmed the therapeutic effect of vanadium compounds on blood glucose 
levels with little side effects [21]. And the mechanism of reduction of blood glucose levels by vanadium compounds has been reported to be via the activation of PKB/Akt leading to increased uptake of glucose by the GLUT4 transporter [22].

Gasca D herbal formulation has been found in the present study to have Aluminium at a concentration of $16.84 \mu \mathrm{g} / \mathrm{g}$. The mean exposures of the adult population to aluminium from overall diet including additives varied a lot among different countries, ranged from $1.6 \mathrm{mg} / \mathrm{day}$ in most recent French study to more than $34 \mathrm{mg} /$ day [23] in Mainland China [24]. In fact, the dietary exposures to aluminium of some population groups were found to exceed the Provisional Tolerable Weekly Intake PTWI in some countries such as the UK $(1.3 \mathrm{mg} / \mathrm{kg} \mathrm{bw} /$ week for toddlers $(1.5-$ 4.5 years)) [15], Sweden (1.5 mg/kg bw/week for 60-kg females) 2 , and Mainland China ( $4.0 \mathrm{mg} / \mathrm{kg}$ bw/week for $60-\mathrm{kg}$ adults) [24]. Aluminium is present in drinking water at usual levels of less than $0.2 \mathrm{mg} / \mathrm{L}$, and is also present in most foods naturally (normally at levels of less than $5 \mathrm{mg} / \mathrm{kg}$ ). But, some foods such as potatoes, spinach and tea may contain high levels of aluminium naturally. Aluminium is also present in food owing to the use of aluminium-containing food additives, which has been regarded as the main dietary source $[25,26]$. Moreover, it has been reported that soyabased formulae were found to contain high levels of aluminium, leading to concentrations of 0.4 $-6 \mathrm{mg} / \mathrm{L}$ in the ready-to-drink products [26]. No acute toxic effects by the oral exposure to aluminium in the general population have been reported despite its widespread occurrence in foods, drinking water and many antacid preparations [27]. Daily intake of aluminium in antacids and buffered aspirin could be as much as $5 \mathrm{~g}$ and $0.7 \mathrm{~g}$ respectively [26]. For an individual who regularly ingests aluminium-containing medications for long term, exposure to aluminium from medication could be much higher than that from the diet. The concentration of iron in the Gasca $\mathrm{D}$ herbal formulation was the highest among all the elements tested with a concentration of $67.16 \mu \mathrm{g} / \mathrm{g}$. Iron is an essential element that is necessarily required for boosting the red blood cell. The presence of iron may play a significant role to protect, maintain and enhance red blood cell function.

GC-MS analysis of Gasca D herbal formulation shows the presence of 14 important compounds. One of such compounds is beta-alanine, which has been shown to enhance muscular endurance. Beta-alanine supplementation is used by athletes competing in high-intensity track and field cycling, rowing, swimming events and other competitions $[28,29]$. The presence of beta-alanine in Gasca D herbal formulation may be very helpful especially for people with type 2 diabetes who have developed keto acidosis, lactic acidosis due to medication or those who suffer from fatigue, malaise and lack of vigor. Beta-alanine supplementation increases intramuscular L-carnosine concentrations, combining with muscle L-histidine [30]. During moderate to high-intensity exercise, hydrogen ions $(\mathrm{H}+)$ begin to accumulate leading to a drop in intramuscular $\mathrm{pH}$ and ultimately influencing muscle performance [31]. Carnosine has been shown to act as an intracellular buffer to Hydrogen [32], which may help the muscle 'buffer' or withstand the fatigue more effectively. One such compound with buffering capacity found in Gasca D herbal formulation is carbonic acid, which appeared at four different retention time intervals signifying the abundance of this compound in the herbal mixture. Carbonic acid is naturally present in the human body to maintain a normal $\mathrm{pH}$ balance in the blood. Carbonic acid as with most buffers in the human body can be exhausted, they need to be replaced. One of the most common uses of carbonic acid is as a salt form, sodium bicarbonate, for an intravenous infusion in the hospital setting. It is the main buffering compound in human blood and can be broken down to carbon dioxide by an enzyme called carbonic anhydrase. Another compound that has been found to 
influence carbonic anhydrase activity in Gasca D herbal formulation is 1,3,4-Thiadiazol-2-amine. 1,3,4-Thiadiazoles were first described in 1882 by Fischer and further developed by Busch and his coworkers. Thiadiazoles carrying mercapto, hydroxy and amino substituents can exist in many tautomeric forms [33]. They are widely known as compounds with various kinds of biological activities showing anticancer properties against human cancers and acting as diuretic, antibacterial, antifungal, antitubercular and leishmanicidal agents. Many of them exhibit anticonvulsant, antiinflammatory, antidepressant, analgesic and anxiolytic effects. The molecular target of 1,3,4thiadiazoles includes the following enzymes: carbonic anhydrase (CA), cyclooxygenase (CO), neutral endopeptidase (NEP), aminopeptidase N (APN), matrix metalloproteinases (MMPs), phosphodiesterases (PDEs) and c-Src/Abl tyrosine kinase [34].

Paromomycin is another compound identified in Gasca D herbal formulation. Paromomycin is an aminoglycoside antibiotic produced by Streptomyces rimosus var. paromomycinus [35], that has been widely used in human to treat leishmaniasis, cryptosporidiosis, and amebiasis [36] and veterinary medicine for the treatment of various bacterial infections. The antibacterial spectrum of paromomycin is similar to other aminoglycosides that demonstrate broad spectrum activity against some gram-positive and many gram-negative bacteria [27].

\section{CONCLUSION}

In this study the level of some toxic metals were measured and found the most commonly toxic metal to be below the detection limit or in trace amount. The study has also reported the presence of bioactive compounds with biological activity. The results of the study clearly indicate the presence of compounds with pharmacological activities that can be effectively used to treat diseases like cancer, diabetes mellitus, arthritis and inflammation. Further study such as isolation and bioassay of these derivatives should be carried out in the future.

\section{ACKNOWLEDGMENT}

The authors are thankful to the entire staffs of Multi-user Science Research Laboratories Ahmadu Bello University Zaria, Nigeria for their help and advice in the conduct of this study.

\section{CONFLICT OF INTEREST}

The authors declare no conflict of interest.

\section{Reference}

1. WHO, Traditional Medicine Strategy (2002-2005). WHO/EDM/TRM/2002.1. Geneva, Switzerland 2002b: World Health Organization.

2. Willcox M.L.; Bodeker, G. Traditional herbal medicines for malaria. BMJ 2004;329:11569. PMID:15539672 doi:10.1136/bmj.329.7475.1156

3. Mukherjee,P.W. Quality Control of Herbal Drugs: An Approach to Evaluation of Botanicals. New Delhi, India: Business Horizons Publishers 2002.

4. Bodeker, C., Bodeker, G., Ong, C.K., Grundy, C.K., Burford, G., and Shein, K. WHO Global Atlas of Traditional, Complementary and Alternative Medicine. Geneva, Switzerland: World Health Organization 2005.

5. Bandaranayake,W.M. Qualitycontrol,screening,toxicity,andregulation of herbaldrugs,"in Modern Phytomedicine. Turning Medicinal Plants into Drugs, eds I. Ahmad, F. Aqil, and 
M. Owais (Weinheim: Wiley-VCHGmbH \& Co. KGaA), 2006 25-57. doi:10.1002/9783527609987.

6. Barnes, J. Quality, efficacy and safety of complementary medicines: fashions, facts and the future. Part1: Regulation and quality. Br J. Clin. Pharmacol. 2003, 55: 226-233.

7. Zaleska, A. Heavy metals: health and environmental effects of some heavy metals (concentration on RoHS Directive), Gdańsk. Chemical Faculty, Gdańsk University of Technology PG Press. 2008, pp. 1-27.

8. Phillips, S; Balge, M. Heavy metal toxicity, Texas (SA). New Fields, 2007 1-30.

9. WHO guidelines on safety monitoring of herbal medicines in pharmacovigilance systems, World Health Organization Press, Geneva, 2004

10. Gupta S, Pandotra P, Gupta AP, Dhar JK, Sharma G, Ram G, Husain MK. Bedi YS, Volatile (As and $\mathrm{Hg}$ ) and non-volatile $(\mathrm{Pb}$ and $\mathrm{Cd}$ ) toxic heavy metals analysis in rhizome of Zingiber officinale collected from different locations of North Western Himalayas by Atomic Absorption Spectroscopy. Food Chem. Toxicol., 2010, 48, 2966-2971

11. WHO Quality control methods for medicinal plant materials Published by WHO Geneva 1998

12. Khan, S.A., L. Khan, I. Hussain, K.B. MarwatandN. Ashtray. Profile of heavy metals in selected medicinal plants. Pakistan Journal of Weed Science Research, 2008 14(1-2): 101110.

13. Wolrd Health Organization "Summary and conclusions of the 61st meeting of the joint FAO/WHO expert committee on food additives (JEFCA)" JEFCA/61/sc, 2003. Rome, Italy

14. Chionyedua T.O; Ngozi A; Isiaka A.O. Levels of Potentially Toxic Metals In Selected Herbal Medicines in Lagos, Nigeria. Journal of Natural Sciences Research. 2015, 5; 2; 148

15. Health Canada. Canadian Total Diet Study. Dietary Intakes of Contaminants \& Other Chemicals for Different Age-Sex Groups of Canadians. 2007 Available at URL: http://www.hc-sc.gc.ca/fn-an/surveill/total-diet/intake-apport/chem_age-sex_chim_2007eng.php\

16. Tokalioğlu, S. Determination of trace elements in commonly consumed medicinal herbs by ICP-MS and multivariate analysis. Food Chemistry, 2012. 134, 2504-2508.

17. Bogdan S, Marek W. Central European Journal of Medicine The analysis of heavy metals content in herbal infusions. Cent. Eur. J. Med. 2012, 7(4) ;; 457-464

18. Jabeen, S.; Shah, M.T; Khan S. and Hayat M.Q. Determination of major and trace elements in ten important folk therapeutic plants of Haripur basin, Pakistan.Journal of Medicinal Plants Research, 2010 4(7). 559-566.

19. Rehder D. The role of vanadium in biology. Metallomics, 2015, DOI: 10.1039/C4MT00304G.

20. Thompson KH, Orvig C. Vanadium in diabetes: 100 years from Phase 0 to Phase I. J Inorg Biochem, 2006, 100: 1925-1935.

21. Thompson KH, Lichter J, LeBel C, Scaife MC, McNeill JH, Orvig C. Vanadium treatment of type 2 diabetes: a view to the future. J Inorg Biochem 2009,103: 554-558.

22. Vardatsikos G, Mehdi MZ, Srivastava AK. Bis(maltolato)-oxovanadium (IV)-induced phosphorylation of PKB, GSK-3 and FOXO1 contributes to its glucoregulatory responses (review). Int J Mol Med, 2009, 24: 303-309. 
23. FSAI.R report on a Total Diet Study carried out by the Food Safety Authority of Ireland in the period 2001-2005. 2011 Available at URL: www.fsai.ie/WorkArea/DownloadAsset.aspx?id=11097

24. Committee on Toxicity of Chemicals in Food, Consumer Products and the Environment (COT). 2008. COT Statement on the 2006 UK Total Diet Study of Metals and Other Elements.

25. IPCS. Aluminium. Environmental Health Criteria 194. Geneva: WHO. 1997

26. Centre for Food Safety. Chemical Hazard Evaluation: Aluminium in Food. Risk Assessment Studies Report No.35. 2009

27. Wong WWK; Chung SWC; Kwong KP, Ho YY, Xiao Y. 2010. Dietary exposure to aluminium of the Hong Kong population. Food Additives and Contaminants Part A; 2010; 27(4):457-63.

28. Hill, C. A., Harris, R. C., Kim, H. J. Influence of beta-alanine supplementation on skeletal muscle carnosine concentrations and high intensity cycling capacity. Amino acids, 2007. 32(2), 225-233.

29. Saunders, B; Elliott-Sale, K; Artioli, G. G; Swinton, P. A; Dolan, E; Roschel, H and Gualano, B. $\beta$-alanine supplementation to improve exercise capacity and performance: a systematic review and meta-analysis. British Journal of Sports Medicine, 2016, 51, 626627

30. Blancquaert, L., Everaert, I., and Derave, W. Beta-alanine supplementation, muscle carnosine and exercise performance. Current Opinion in Clinical Nutrition \& Metabolic Care, 2015, 18(1), 63-70.

31. Culbertson, J. Y., Kreider, R. B., Greenwood, M., and Cooke, M. Effects of beta-alanine on muscle carnosine and exercise performance: a review of the current literature. Nutrients, 2010, 2(1), 75-98.

32. Hobson R. M., Saunders, B., Ball, G. Effects of b-alanine supplementation on exercise performance: a meta-analysis. Amino Acids, 2012; 43:25-37.

33. Kornis, G. 1,3,4-Thiadiazoles. Comprehensive heterocyclic chemistry. 1984, 6; 545-577

34. Matysiak J. Biological and pharmacological activities of 1,3,4-thiadiazole based compounds. Mini Rev Med Chem. 2015;15, 9,762-75.

35. The Merck Index. 12th Edition, Merck Research Laboratories, Whitehouse Station NJ, 1997.

36. Murray, H.W; Berman, J.D; Davies, C.R.; Saravia, N.G. Advances in Leishmaniasis. The Lancet 2005, 366, 1561-1577.

37. Stead, D.A. Current Methodologies for the Analysis of Aminoglycosides. J. Chromatogr. $B$ 2000, 747, 69-93. 